\title{
Dissemination of hepatocellular carcinoma is mediated via chemokine receptor CXCR4
}

\author{
CC Schimanski*,', R Bahre', I Gockel'², A Müller', K Frerichs², V Hörner', A Teufel', N Simiantonaki ${ }^{3}$, \\ S Biesterfeld ${ }^{3}$, T Wehler ${ }^{4}$, M Schuler $^{4}$, T Achenbach ${ }^{5}$, T Junginger ${ }^{2}$, PR Galle' and M Moehler' \\ 'First Department of Internal Medicine, Johannes Gutenberg University of Mainz, Langenbeckstrasse I, 55 I 0 I Mainz, Germany; ${ }^{2}$ Department of Surgery, \\ Johannes Gutenberg University of Mainz, Mainz, Germany; ${ }^{3}$ Department of Pathology, Johannes Gutenberg University of Mainz, Mainz, Germany; ${ }^{4}$ Third \\ Department of Internal Medicine, Johannes Gutenberg University of Mainz, Mainz, Germany and ${ }^{5}$ Department of Radiology, Johannes Gutenberg \\ University of Mainz, Mainz, Germany
}

In different tumour entities, expression of the chemokine receptor 4 (CXCR4) has been linked to tumour dissemination and poor prognosis. Therefore, we evaluated, if the expression of CXCR4 exerts similar effects in human hepatocellular carcinoma (HCC). Expression analysis and functional assays were performed in vitro to elucidate the impact of CXCLI 2 on human hepatoma cells lines. In addition, expression of CXCR4 was evaluated in 39 patients with HCC semiquantitatively and correlated with both, tumour and patients characteristics. Human HCC and hepatoma cell lines displayed variable intensities of CXCR4 expression. Loss of p53 function did not impact on CXCR4 expression. Exposure to CXCLI2 mediated a perinuclear translocation of CXCR4 in Huh7/ Hep3B cells and increased the invasive potential of Huh7 cells. In HCC patients, CXCR4 expression significantly correlated with progressed local tumours (T-status; $P=0.006$ ), lymphatic metastasis $(\mathrm{N}$-status; $P=0.005$ ) and distant dissemination (M-status; $P=0.009)$, as well as with a decreased 3-year-survival rate $(P=0.01)$. In summary, strong expression of CXCR4 is significantly associated with progressed hepatocellular cancer.

British Journal of Cancer (2006) 95, 210-217. doi:10.1038/sj.bjc.660325 I www.bjcancer.com

Published online 4 July 2006

(c) 2006 Cancer Research UK

Keywords: CXCR4; chemokine; liver; hepatocellular; metastasis

Hepatocellular carcinoma (HCC) ranges among the most frequent cancer entities worldwide with an incidence of more than 500000 cases per year and raising incidence rates in Western countries (Parkin et al, 2001). While mortality rates of many cancer entities are decreasing, hepatocellular cancer revealed an significant increase of death rates during the 1990s (Wingo et al, 2003). HCC is associated with liver cirrhosis commonly resulting from inflammatory liver disease, such as chronic hepatitis B (HBV), hepatitis $\mathrm{C}(\mathrm{HCV})$ and to a lesser extent from autoimmunetriggered hepatitis or cholangitis (AIH, PBC, PSC), but also from nonviral diseases, such as chronic alcohol intake or exposure to mycotoxin and aflatoxin B1 (Bosch et al, 1999). Hepatocarcinogenesis is considered a slow process in which diverse genomic alterations accumulate, altering the phenotype of hepatocytes and hence leading to multiple monoclonal and dysplastic hepatocyte populations (Thorgeirsson and Grisham, 2002). As progress of dysplastic hepatocytes to HCC might occur simultaneously in different foci or nodules, variable genomic alterations can be found within the same liver indicating a genetic heterogeneity of lesions (Feitelson et al, 2002). Molecular determinants including

*Correspondence: Dr CC Schimanski;

E-mail: dr_schimanski@yahoo.de

Received 3 February 2006; revised 23 May 2006; accepted 12 June 2006; published online 4 July 2006 mutations and loss of heterozygosity $(\mathrm{LOH})$ in certain tumoursuppressor genes (i.e. p53, IGF2R, RB1, PTEN) and oncogenes (i.e. $\mathrm{N}$-ras, E2F4) have recently been proposed and summarised in the pathway of molecular pathogenesis of human HCC (Feitelson et al, 2002; Thorgeirsson and Grisham, 2002). Nonetheless, it seems very likely that additional pathogenic alterations instrumentally mediate the progression and dissemination of human HCC.

Tumour growth and metastatic dissemination are deemed to result from an intricate, dysregulated molecular machinery leading to diverse phenomena in tumour cells, such as resistance to the induction of apoptosis, immune escape mechanisms as well as invasion and migration capabilities. Recent data suggest that chemokine receptors may direct lymphatic and hematogenous spreading and may furthermore influence the sites of metastatic growth of different tumours (Arya et al, 2003).

Chemokines and their G-protein-coupled receptors were originally reported to mediate different pro- and anti-inflammatory responses (Zlotnik and Yoshie, 2000). The chemokine receptor 4 (CXCR4) was described to regulate the homing of lymphocytes in inflammatory tissues (Murdoch, 2000). Its natural ligand, CXCL12 (stromal cell-derived factor 1 alpha (SDF-1 $\alpha)$ ), is highly expressed by endothelial cells and in tissues of metastatic growth, such as lung, liver and lymph nodes, and attracts lymphocytes into these organs (Phillips et al, 2003). Increased CXCL12 production by biliary epithelial cells and proliferating bile ductules in diverse inflammatory liver diseases might play an 
additional role in the recruitment of CXCR4-positive inflammatory cells into the inflamed livers (Terada et al, 2003). Further data indicate that CXCR4 may be involved in the retention of alloactivated lymphocytes at sites of graft damage after liver transplantation (Goddard et al, 2001). Most recently, CXCR4 has shifted into focus as it might play an important role in tumour spreading.

High CXCR4 expression was associated with tumour dissemination in colorectal, breast and oral squamous cell carcinoma (Chen et al, 2003; Uchida et al, 2003; Schimanski et al, 2005). Supporting data from in vitro and murine in vivo tumour models underlined the key role of CXCR4 for tumour cell malignancy, as activation of CXCR4 induced migration, invasion and angiogenesis of cancer cells (Mori et al, 2004). Furthermore, downregulation of CXCR4 in melanoma cells led to decreased pulmonary metastasis in mice, both in number and size (Murakami et al, 2002).

However, no data are presently available on the expression of CXCR4 in human HCC and its impact on disease progression and prognosis. Therefore, we evaluated the expression of CXCR4 in hepatoma cell lines and HCC specimens and correlated the results with the patients' clinicopathological parameters and survival. Furthermore, we elucidated the impact CXCL12 exposure on CXCR4 localisation and on cellular proliferation and invasion, as well as of p53 function on CXCR4 expression.

\section{MATERIALS AND METHODS}

\section{Cell culture}

The human hepatoma cell lines Huh-7, Hep3B as well as CXCR4 deficient HepG2 and p53 dominant-negative transfected HepG2 were cultured in DMEM (Invitrogen, Germany) supplemented with $10 \%$ FCS, 100 units $\mathrm{ml}^{-1}$ penicillin, $100 \mu \mathrm{g} \mathrm{ml}^{-1}$ streptomycin (Cambrex, Germany) and $1 \mathrm{~mm}$ L-glutamine (Invitrogen, Germany). P53 Dominant-negative transfected HepG2 were kindly provided by M Schuler (Third Departement of Internal Medicine, Johannes Gutenberg University, Mainz, Germany).

\section{Western blot analysis}

Huh-7, Hep3B, HepG2 and p53 dominant-negative transfected HepG2 cells were washed with PBS and lysed in 0.5\% NP-40 solution. Of protein $100 \mu \mathrm{g}$ was loaded on an 10\% SDS-PAGE gel. The gel was transferred onto a PVDF membrane following seperation. The respective proteins were detected with antiCXCR-4 (1:500, CIO115, Capralogics, USA; $1: 1000$ donkey antigoat IgG 2nd antibody SC-2020 by Santa Cruz Biotechnology, CA, USA) and antiactin (1:1000, A2066, Sigma, Germany; $1: 1000$ goat anti-rabbit IgG 2 nd antibody $170-6515$ by Biorad, USA) and were visualised by ECL Western Blotting Analysis System (Amersham Biosciences, USA).

\section{Translocation assays}

Translocation of CXCR4 under CXCL12 exposure was assayed in Huh-7, Hep3B and HepG2 cells. In brief, cells were seeded on chamber-slides and treated with CXCL12 (100 $\mathrm{ng} \mathrm{ml}^{-1}$; Sigma, Germany) for 0,2 or $24 \mathrm{~h}$. IHC-CXCR4 staining and evaluation was performed as described below. To prove the observed effects, Huh7, Hep3B and HT29 cells were grown in chamber slides and exposed to CXCL12 for 0 or $2 \mathrm{~h}$. After washing with PBS, the cells were fixed in methanol/acetone for $2 \mathrm{~min}$. For immunofluorescence staining an anti-goat-FITC-conjugated IgG secondary antibody (F2016, Sigma, Germany) was used. Hoechst 33342 (Molecular Probes, Netherlands) was applied to stain nuclei. The cells were imaged directly in the chambers using a Zeiss LSM 510UV laser scanning microscope.

\section{FACS analysis}

HT29 cells were grown in 12-wells in DMEM (Invitrogen, Germany) supplemented with $10 \%$ FCS, 100 units $\mathrm{ml}^{-1}$ penicillin, $100 \mu \mathrm{g} \mathrm{ml}^{-1}$ streptomycin (Cambrex, Germany) and $1 \mathrm{~mm}$ L-glutamine (Invitrogen, Germany). One day before analysis FCS concentration was reduced to $1 \%$. During analysis, cells were treated with CXCL12 for 0 or $2 \mathrm{~h}$. After trypsination, cells were washed three times with PBS, finally solved in $25 \mu \mathrm{l}$ PBS and blocked with $25 \mu \mathrm{l}$ human fresh frozen plasma for $15 \mathrm{~min}$ at room temperature. Hereafter, $2 \mu \mathrm{l}$ of PE-conjugated anti-CXCR4 (Clone 12G5; BD Biosciences, Belgium) were added and incubated for $45 \mathrm{~min}$ at $37^{\circ} \mathrm{C}$. Cells were again washed in $\mathrm{PBS}$ and finally analysed in a FACSCalibur (BD Biosciences; Belgium).

\section{Proliferation assays}

Cells (Huh-7, Hep3B and HepG2 cells) $\left(5 \times 10^{3}\right)$ were plated in 96wells. After seeding, cells were either exposed to CXCL12 (Sigma, Germany) or the equivalent amount of solvent (0.1\% BSA in PBS). The amount of cells per well was determined daily by luminescence assay according to the recommendations of the manufacturer (Celltiter-Glo, Cell Viability assay, Promega, USA). Each condition was performed in quadruplicates.

\section{Cellular migration/invasion assays}

Invasion of Huh-7, Hep3B and HepG2 cells was assayed with the extracellular matrix covered QCM Chemotaxis 96-well cell invasion assay ( $8 \mu \mathrm{M}$ pore size; QCM Chemotaxis $96-$ well cell invasion assay kit; Chemicon International, USA). In brief, cells were serum starved for $24 \mathrm{~h}$ before initiation of the assay. Cells $\left(4 \times 10^{4}\right)$ were resuspended in serum-free DMEM and added to the upper chamber. Consecutively, DMEM with $20 \%$ FCS and $\pm 100 \mathrm{ng} \mathrm{ml}^{-1}$ CXCL12 was added to the lower chamber. Chambers were incubated for $24 \mathrm{~h}$ at $37^{\circ} \mathrm{C}$ in a humid atmosphere of $5 \% \mathrm{CO}_{2}$. After incubation, the amount of invaded and migrated cells in the lower chamber was determined by fluorescence assay performed according to the recommendations of the manufacturer. Each condition was performed in quadruplicates.

\section{Tissue samples}

Hepatocellular carcinoma tissue samples were obtained from 39 patients undergoing liver biopsy, hemihepatectomy or orthotopic liver transplantation for HCC at the University of Mainz. The morphological classification of the carcinomas was conducted according to World Health Organization (WHO) specifications. Patients were followed up on a regular basis depending on the procedure performed.

\section{Immunohistochemical staining}

The avidin-biotin-complex method was used to detect the protein CXCR-4 (anti-CXCR-4, dilution 1:300; Capralogics, USA). Formalin-fixed and paraffin-embedded tissue were deparaffinised and subsequently microwaved in EDTA buffer. After preincubation with hydrogen peroxide, avidin/biotin blocking kit (Vector Laboratories Inc., USA) and rabbit serum (Vector Laboratories Inc., USA) the primary antibodies were applied for $1 \mathrm{~h}$ at room temperature. After incubation with the secondary antibody (rabbit anti-goat biotinylated; dilution 1:200, Vector Laboratories Inc., USA), the avidin-biotin-complex was added and the enzyme activity visualised with diaminobenzidine. Counterstaining was performed with haematoxylin. For negative controls only the secondary antibody was used. A negative control was performed for every HCC sample $(N=39)$. For positive controls formalin- 


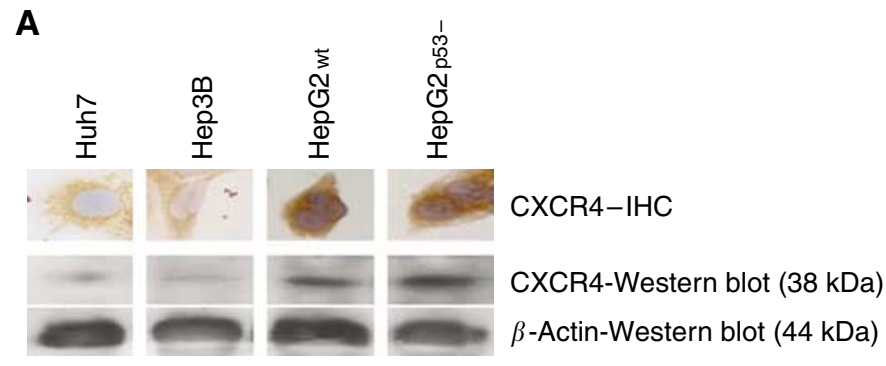

B
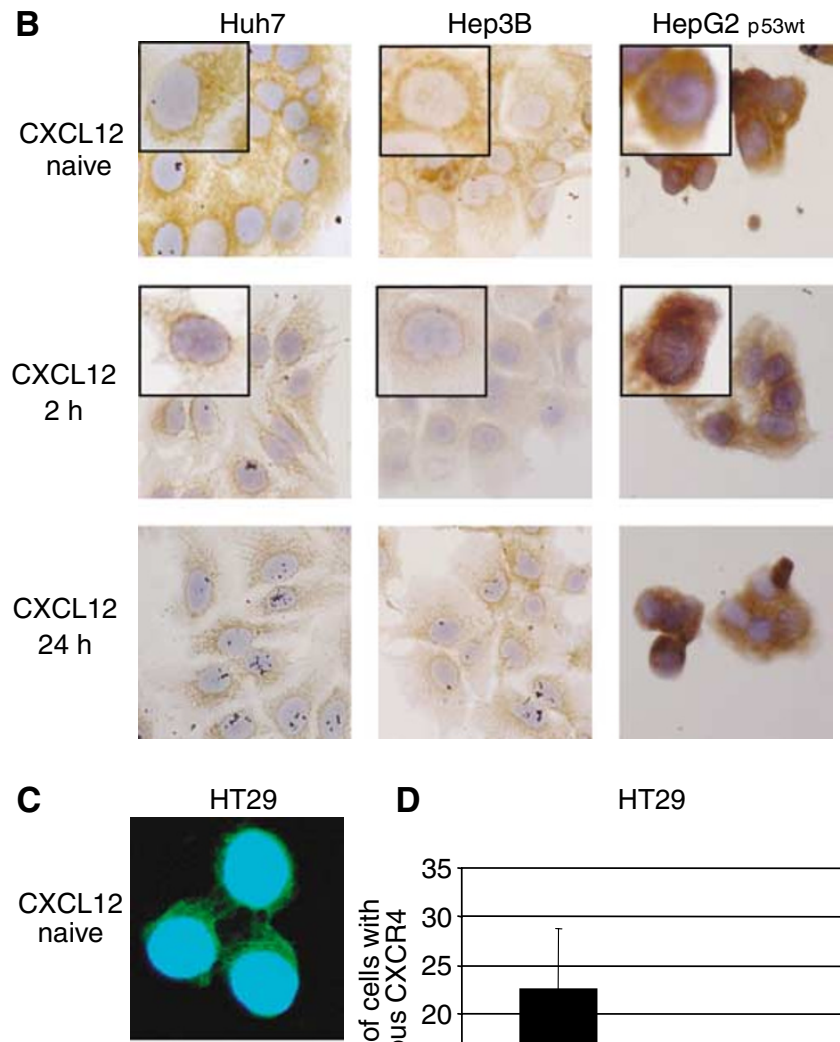

D

HT29

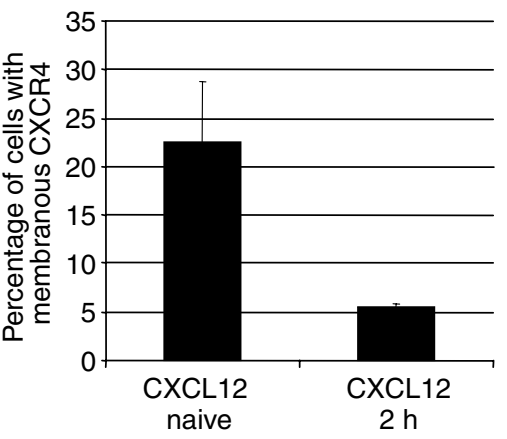

Figure I (A) Expression and immunohistochemical staining of CXCR4 in diverse human hepatoma cell lines. Huh7 and Hep3B cells revealed a weak CXCR4 expression, whereas HepG2 cell lines depicted medium CXCR4 staining, independent from p53 status. (B) Exposure to CXCLI2 mediated a rapid perinuclear translocation of CXCR4 from the cytoplasma and membrane (inlet patch). This translocation was strongly evident in Huh7 and also in Hep3B cells, but absent in HepG2 cells. (C) Fusion of nuclear staining (blue) and CXCR4 staining (green). Exposure to CXCLI2 mediated a rapid cytoplasmatic clearance and perinuclear translocation of CXCR4 in HT29. (D) FACS analysis revealed a significantly decreased amount of positive HT29 cells for membrane-bound-CXCR4 upon CXCLI2 exposure.

fixed and paraffin-embedded tissue samples of the human spleen were applied.

\section{Evaluation of immunostaining}

Immunostaining was evaluated semiquantitatively by three authors independently (CCS, RB, NS), blinded to patient outcome and all clinicopathologic findings. The immunohistochemical staining was analysed according to a scoring method that we have previously validated and described (Schimanski et al, 2005): the tumours were classified into four groups based on the homogenous staining intensity: 0 , absent; 1 , weak; 2 , intermediate; 3 , strong staining. In the case of heterogeneous staining within the same sample, the respective, 0.5 points higher score was chosen, if more than $50 \%$ of cells revealed the higher staining intensity. If the evaluations did not agree the specimens were re-evaluated and then classified according to the assessment given most frequently by the observers. 
A
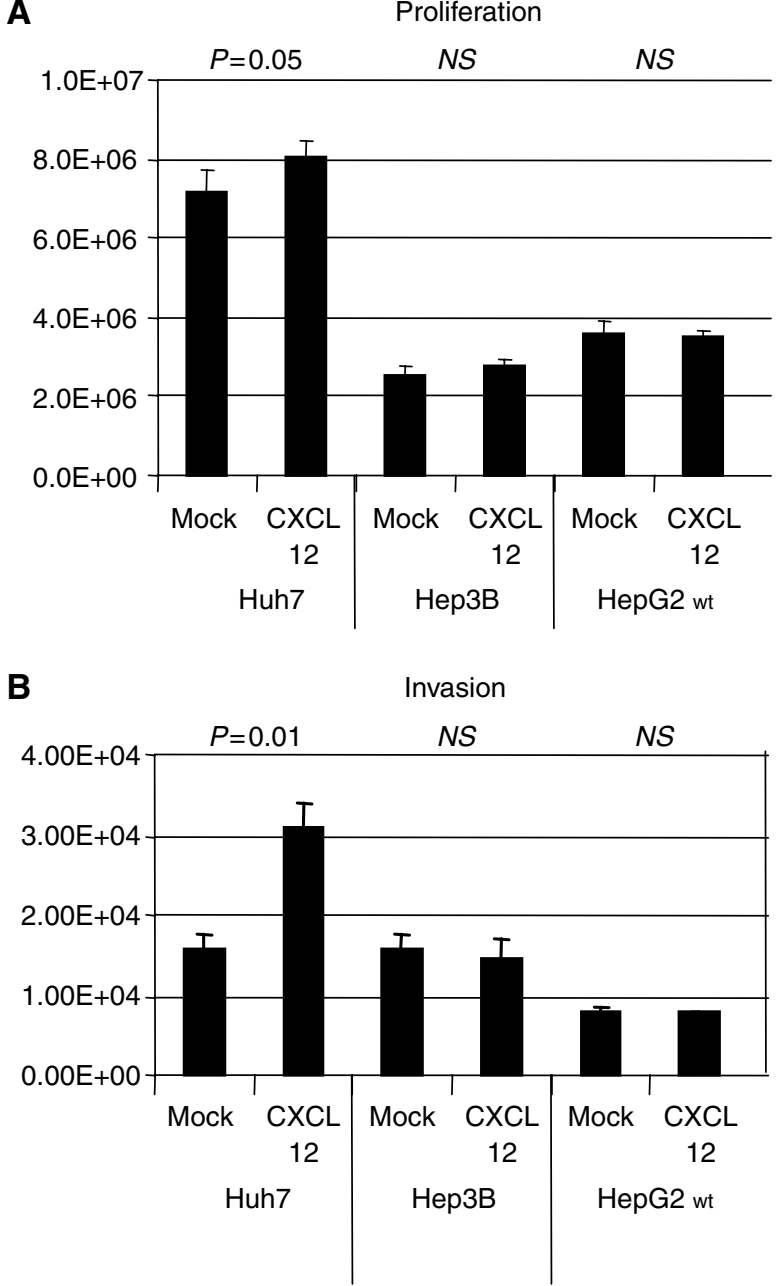

Figure 2 (A and $\mathbf{B}$ ) Exposure to $\mathrm{CXCL}$ /2-induced proliferation and invasion of Huh7, but not of Hep3B or HepG2 cells. While the impact of CXCLI 2 on invasion was highly significant, it was only marginally significant on proliferation.

\section{Statistics}

The association of staining intensity with clinicopathological patterns was assessed with the $\chi^{2}$-test and with the unpaired Student's $t$-test, when appropriate. Survival rates were visualised applying the Kaplan-Meier curves, and $P$-values were determined by the log-rank test. $P<0.05$ was considered significant and $P<0.001$ highly significant in all statistical analyses.

\section{RESULTS}

\section{CXCR4 expression in hepatoma cell lines}

CXCR4 expression analysis of human hepatoma cell lines revealed varying expression intensities as depicted by Figure 1A. CXCR4immunostaining results correlated with the respective Western blot analysis (Figure 1A). CXCR4 immunostaining and Western blot analysis correlated with the respective immunofluorescence profile (confirmatory results not shown). Notably, p53 did not impact on CXCR4 expression.

\section{Translocation assays}

CXCL12 induced translocation of CXCR4 from the membrane and cytoplasma to the perinuclear region was present in Huh7 and
Table I Patient and tumour characteristics

\begin{tabular}{|c|c|}
\hline & Patient characteristics \\
\hline Total number & 39 \\
\hline Median age (years) & 60.6 \\
\hline \multicolumn{2}{|l|}{ Gender } \\
\hline Female & $4(10 \%)$ \\
\hline Male & $35(90 \%)$ \\
\hline \multicolumn{2}{|l|}{ T-status } \\
\hline । & $8(20 \%)$ \\
\hline 2 & $10(26 \%)$ \\
\hline 3 & $16(41 \%)$ \\
\hline 4 & $5(13 \%)$ \\
\hline \multicolumn{2}{|l|}{ N-status } \\
\hline 0 & 24 (62\%) \\
\hline I & $10(26 \%)$ \\
\hline 2 & $4(10 \%)$ \\
\hline Unknown & I (2\%) \\
\hline \multicolumn{2}{|l|}{ M-status } \\
\hline 0 & $26(67 \%)$ \\
\hline I & $12(31 \%)$ \\
\hline Unknown & I (2\%) \\
\hline \multicolumn{2}{|l|}{ Grading } \\
\hline 1 & $3(8 \%)$ \\
\hline 2 & 25 (64\%) \\
\hline 3 & II (28\%) \\
\hline 3-year-survival & $54 \%$ \\
\hline
\end{tabular}

Hep3B cells, but absent in CXCR4-defecient HepG2 cell lines, which were used as a negative control and proof of principle in all functional assays (Figure 1B). Immunofluorescence analysis revealed, that exposure to CXCL12 mediated a rapid cytoplasmatic clearance and translocation of CXCR4 in Huh7 and Hep3B (confirmatory data not shown) and in HT29 (Figure 1C).

\section{FACS analysis}

CXCL12 mediated a rapid decrease of HT29 cells positive for membrane-bound CXCR4 (-CXCL12: 22.46\%; s.d. 6.24; + CXCL12: 5.49\%; s.d. 0.38; $P<0.01)$.

\section{Proliferation assays}

The chemokine CXCL12 slightly stimulated proliferation of Huh-7 (Luminescence on day 4: $8037688 \pm 395512$ IE vs $7146940 \pm 586960$ IE; $P=0.05$ ), but not of Hep3B (Luminescence on day 4: $2745528 \pm 147741$ IE vs $2533050 \pm 254525$ IE; NS) or HepG2 (Luminescence on day 4: $3517047 \pm 173299$ IE vs $3598328 \pm 294455$ IE; NS) hepatoma cells (Figure 2A).

\section{Migration/invasion assays}

The chemokine CXCL12 significantly stimulated migration of Huh-7 (Fluorescence: $30880 \pm 3298$ IE vs $15705 \pm 1801$ IE; $P=0$ .001 ), but not of Hep3B (Fluorescence: $14367 \pm 2694$ IE $v s 15885 \pm$ 1559 IE; NS) or HepG2 (Fluorescence: $7608 \pm 110$ IE $v s 7956 \pm 416$ IE; NS) hepatoma cells (Figure 2B).

\section{Tumour characteristics and patient profiles}

The selected group of patients represent the typical characteristics of hepatocellular cancer in industrialised countries, except for a 
A

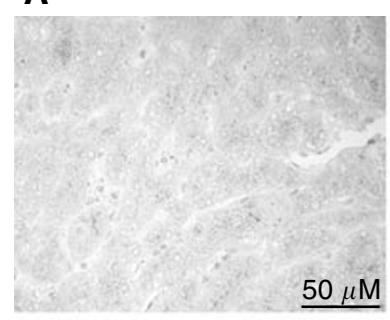

Weak
CXCR4-cytoplasmatic staining

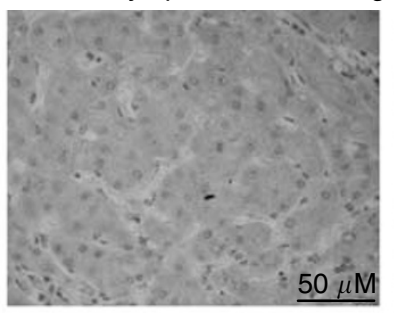

Medium

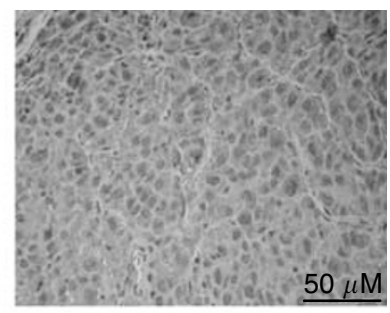

Strong

CXCR4-membranous staining

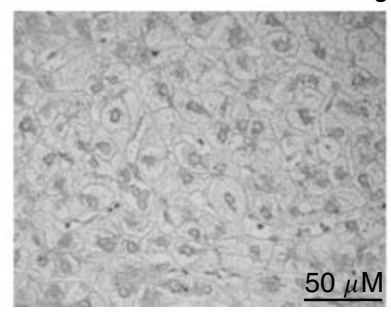

B

Survival dependent on CXCR4 expression

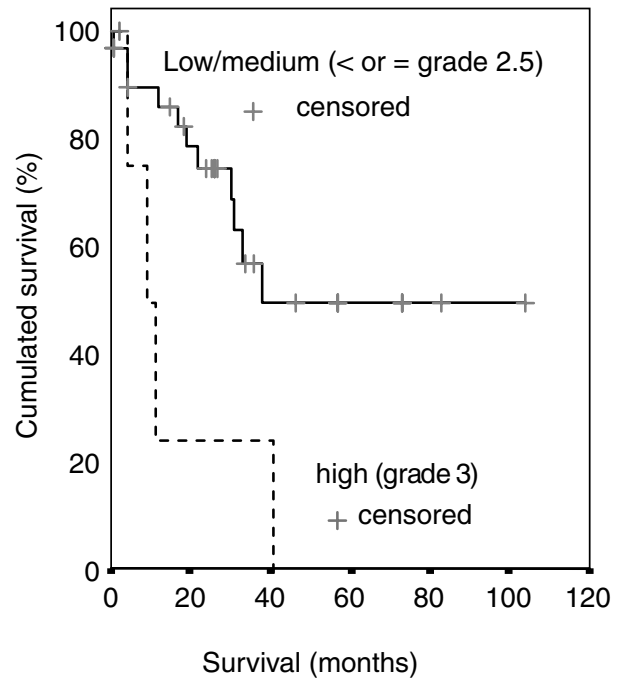

Figure 3 (A) Depicts the respective cytoplasmatic expression grades of CXCR4 (weak; medium and strong) as well as a rare sample of a membranous CXCR4 staining. (B) The probability of survival of HCC patients is given in relation to time after histological confirmation. Patients with grade 3 CXCR4 expression showed a significantly reduced 3-year-survival rate as compared to all other patients $(P=0.0 \mathrm{I})$.

lower percentage of female patients and a prolonged survival resulting from hemihepatectomy and orthotopic liver transplantation for HCC. Patients characteristics are depicted in Table 1.

\section{Immunohistochemical staining of CXCR4 in HCC}

The staining for CXCR4 revealed predominantly a cytoplasmatic, and in few specimens an additional weak membranous or nuclear location of CXCR4 (Figures 3A-D). The respective expression rate for CXCR4 was $100 \%$ (39 out of 39 ) and varied from weak (8\%), intermediate $(56 \%)$ to strong $(36 \%)$.

Negative controls of human hepatocellular cancer remained negative for every tissue sample $(N=39$, not shown). Splenic lymphocytes revealed a strong CXCR4 expression matching human hepatocellular cancer tissue or cell lines with strong expression of
CXCR4. Similarly, inflammatory infiltates of the liver depicted a strong CXCR4 expression.

\section{Relevance of CXCR4 expression in HCC}

Strong CXCR4 expression did correlate with local progression and proliferation of the primary tumour as indicated by the T-status (TNM classification; $P=0.006$; Table 2), with lymph node involvement (N-status; $P=0.005)$ and with distant metastases (M-status; $P=0.009$; Table 2). Evidently, CXCR4 expression did not have impact on the grading, medium age or gender. Concerning survival, a strong CXCR4 expression (grades 2.5 and $3)$ could not be significantly correlated with survival $(P=0.2)$. Noteworthy, if a subgroup with grade 3 expression (homogenous strong expression) was compared to the rest (heterogenous strong or lower) a decreased 3-year-survival rate of $25 \%$, as compared to 
$57 \%$ was observed. This difference is depicted in the respective survival plot (Figure 3B, log rank $P=0.01$ ).

\section{DISCUSSION}

So far, no data have been available on the expression of CXCR4 in human HCC and its impact on disease progression and prognosis. In other tumour entities, expression of the chemokine receptor CXCR4 has been linked to tumour dissemination and poor prognosis. Therefore, we analysed the expression profile of CXCR4 in a series of human hepatoma cell lines and HCC patients. Diverse external factors, such as hypoxia (hif-1-pathway) and the activation of adenosine receptors, as well as internal cellular alterations like the inactivation of tumour-suppressor genes $\mathrm{pVHL}$, p53 or the overexpression of NFkB have been defined as important molecular regulators of the CXCR4 expression (Helbig et al, 2003; Staller et al, 2003; Mehata et al, 2004). To verify the regulation of CXCR4 by p53 in human HCC, we investigated the CXCR4 expression profile in p53 $\mathrm{wt}$ and dominant-negative transfected HepG2 cells, Huh7 and Hep3B cells (Figure 1A and B). The human hepatoma cell lines analysed revealed different intensities of a predominantly cytoplasmatic CXCR4 expression. Interestingly, the p53 dominant-negative HepG2 cells revealed unchanged levels of CXCR4 expression as compared to wt HepG2 cells, failing to confirm a regulatory mechanism of p53 on CXCR 4 expression in transformed hepatic cells, although a p53-mediated impact on CXCR4 expression has been previously proposed for other cell lines (Mehata et al, 2004). Exposure to CXCL12, the ligand of CXCR4, mediated a rapid perinuclear translocation of CXCR4 in Huh7 and Hep3B, but not in HepG2 cells within two hours, indicating a cellular activation with pseudopodia formation as classically observed in epithelial mesenchymal transition (EMT). A

Table 2 Patient and tumour characteristics dependent on intensity of CXCR4 expression

\begin{tabular}{|c|c|c|c|c|}
\hline & \multicolumn{3}{|c|}{ CXCR4 expression } & \multirow[b]{2}{*}{ Statistics } \\
\hline & Weak (I) & Intermediate (2) & Strong (3) & \\
\hline Total number & $3(8 \%)$ & $22(56 \%)$ & $14(36 \%)$ & \\
\hline Average age (years) & & 61.2 & 60.4 & NS \\
\hline \multicolumn{5}{|l|}{ Gender } \\
\hline $\begin{array}{l}\text { Female } \\
\text { Male }\end{array}$ & & $\begin{array}{c}2 \\
23\end{array}$ & $\begin{array}{l}2 \\
12\end{array}$ & NS \\
\hline \multicolumn{5}{|l|}{ T-status } \\
\hline $1+2$ & & 16 & 2 & $P=0.006$ \\
\hline $3+4$ & & 9 & 12 & \\
\hline \multicolumn{5}{|l|}{$N$-status ${ }^{a}$} \\
\hline 0 & & 20 & 4 & $P=0.005$ \\
\hline+ & & 5 & 9 & \\
\hline \multicolumn{5}{|l|}{$M$-status ${ }^{\mathrm{a}}$} \\
\hline 0 & & 21 & 5 & $P=0.009$ \\
\hline+ & & 4 & 8 & \\
\hline \multicolumn{5}{|l|}{ Grading } \\
\hline $1+2^{\circ}$ & & 17 & 11 & NS \\
\hline $3+4$ & & 8 & 3 & \\
\hline 3-year-survival & & $\begin{array}{l}53 \% \\
58 \%\end{array}$ & $\begin{array}{l}55 \% \\
25 \%\end{array}$ & $\begin{array}{c}N S \\
P=0.01\end{array}$ \\
\hline
\end{tabular}

${ }^{a} \mathrm{~N}$ and $\mathrm{M}$ status could not be obtained from one patient. NS = not significant. clathrin-mediated endocytosis following activation and perinuclear translocation of CXCR4 to the perinuclear rab4-, rab5- and rab11-compartment of receptor recycling has previously been reported in human CD34 + haematopoetic progenitor cells (Zhang et al, 2004). Unfortunatelly, FACS analysis of CXCR4 in Huh7 and Hep3B cells previously failed for technical reasons, due to a weak expression level of CXCR4; HepG2 cells could also not be applied due to the defect receptor. In order to confirm the observed translocation in human carcinoma cells we used HT29 cells, which had previously revealed a strong CXCR4 expression and an intact CXCR4 receptor (Schimanski et al, 2005). FACS and immunofluorescence analysis confirmed an internalisation of CXCR4 and a rapid perinuclear translocation upon CXCL12 exposure. In hepatoma cells, exposure to CXCL12 increased proliferation and invasion of Huh7, but not of Hep3B or HepG2 cells. While the impact of CXCL12 on proliferation of Huh7 cells was only marignal, it was significant on invasion. The observed absence of CXCR4 translocation and CXCL12 induced proliferation/invasion in HepG2 cells, confirms earlier data, indicating a loss of chemokine CXCL12-mediated CXCR4 signalling and receptor internalisation in HepG2 cells due to a receptor defect (Mitra et al, 2001). In contrast to HepG2 cells, a defect of the intracellular signal cascade has to be proposed for Hep3B cells, resulting in a resistance to CXCL12-mediated phenomena in spite of receptor translocation. Taken together, our data are in line with in vitro results from other tumour entities, revealing that CXCR4 is essential for proliferation, adhesion, migration and invasion of CXCR4 expressing cancer cells, although the impact of CXCL12 in Huh7 was dramatically stronger on invasion than on proliferation (Mori et al, 2004; Schimanski et al, 2005).

The liver, lungs and lymph nodes are major target organs for metastases of diverse cancers in men. Recent publications on CXCR4 are in line with the 'homing' theory as CXCR4 expression comediates dissemination of primary tumours to different organs through the chemotactic factors CXCL12. Homing factors, influencing chemotaxis to target organs, have been proposed as the filter function of these organs not solely explains the growth of metastases (Stetler-Stevenson and Kleiner, 2001). Herein, chemokine CXCL12 expression seems to be most intense in typical 'homing organs' such as lungs, bone marrow, liver and lymph nodes as compared with other nonhoming tissues (Phillips et al, 2003). Furthermore, endothelial cells, such as pulmonary endothelial cells have been shown to coexpress CXCL12 and vascular cellular adhesion molecule (VCAM)-1, thus mediating tumourcell/endothelial-cell attachment (Cardones et al, 2003). In particular, binding of CXCL12 on CXCR4-induced $\beta$-integrin expression on cancer cells, which was critical to adhesion of cancer cells to VCAM on endothelial cells (Burger et al, 2003). In a murine model only CXCR4 expressing, but not CXCR4deficient CT-26 colon carcinoma cells grew into macrometastases; nonetheless both cell types were able to colonise livers and lungs after injection (Zeelenberg et al, 2003). Interestingly, oval cells, known to express CXCR4 as well, have been reported to migrate to the liver along a CXCL12 gradient, established by injured hepatocytes, inducing oval-cell-aided liver regeneration in hepatitis (Hatch et al, 2002; Mavier et al, 2004). Thus, hepatic tumour dissemination and hepatic regeneration share common pathways of chemotaxis.

In our experiments, immunohistochemical staining of human HCC specimens displayed cytoplasmatic CXCR4 expression with variable intensities, matching the observations made in human colorectal cancer cell lines. A membranous or nuclear localisation of CXCR4 was observed in fewer cases, but an inducible translocation of CXCR4 from the cytoplasma to the membrane has been reported previously (Richard et al, 2004).

In our patients, a strong CXCR4 expression was significantly associated with locally progressed tumours, lymph node and distant metastases. In contrast to other cancer entities, progressed 
T-status of HCC is defined as intrahepatic growth and spread of the respective hepatocellular cancer. Thus, our results not necessarily imply a substantial influence of CXCR4 on the proliferation, but certainly on intrahepatic, lymphatic and hematogenous dissemination of HCC.

Therefore, our results are in line with recent publications from our group and others, reporting a similar effect of CXCR4 on disease dissemination in other tumour entities, such as non-smallcell lung cancer (NSCLC), colorectal or breast cancer (Schimanski et al, 2005). Furthermore, CXCR4 expression was found upregulated in glioblastoma and its consecutive receptor inhibition was followed by tumour cell arrest (Rubin et al, 2003). In osteosarcoma, the level of CXCR4 expression was inversely correlated with overall survival, but positively associated with detection of metastasis (Larverdiere et al, 2004). Likewise, a grade 3 CXCR4 expression in our HCC patients was associated with a significantly reduced 3-year-survival, due to hepatic failure following diffuse intrahepatic HCC dissemination. The prolonged average survival rate of our patients as compared to reported survival rates in standard HCC patients resulted from a high rate of orthotopic liver transplantations in our patient group. Nevertheless, the impact of a strong CXCR4 expression on disease progression might depend on the type and location of the primary carcinoma and most likely on other parameters, which have not been defined yet. In line with this theory, a strong CXCR4 expression was associated with noninvasive gastric cancers and not with lymph node metastases (Kwak et al, 2004).

\section{CONCLUSION}

Certain chemokines have been proposed to distinctly contribute to tumour growth, dissemination and local immune scape (Balkwill and Mantovani, 2001). Our in vitro and in vivo results are in line with these data for human HCC. Strong expression of CXCR4 by HCC was significantly associated with intrahepatic, nodal and distant dissemination. Thus, CXCR4 apparently plays a relevant role during HCC progression. Further efforts will be necessary to evaluate the inhibition of dissemination by CXCR4 antagonists.

\section{ACKNOWLEDGEMENTS}

Immunofluorescence pictures were kindly provided by Dennis Strand, PhD, first Department of Internal Medicine, Johannes Gutenberg University of Mainz, Germany.

\section{REFERENCES}

Arya M, Patel HR, Williamson M (2003) Chemokines: key players in cancer. Curr Med Res Opin 19: 557-564

Balkwill F, Mantovani A (2001) Inflammation and cancer: back to Virchow? Lancet 357: 539-545

Bosch FX, Ribes J, Borras J (1999) Epidemiology of primary liver cancer. Semin Liver Dis 19: 271-285

Burger M, Glodek A, Hartmann T, Schmitt-Graff A, Silberstein LE, Fujii N, Kipps TJ, Burger JA (2003) Functional expression of CXCR4 (CD184) on small-cell lung cancer cells mediates migration, integrin activation, and adhesion to stromal cells. Oncogene 22: 8093-8101

Cardones AR, Murakami T, Hwang ST (2003) CXCR4 enhances adhesion of B16 tumor cells to endothelial cells in vitro and in vivo via beta(1) integrin. Cancer Res 63: 6751-6757

Chen Y, Stamatoyannopoulos G, Song CZ (2003) Down-regulation of CXCR4 by inducible small interfering RNA inhibits breast cancer cell invasion in vitro. Cancer Res 63: 4801-4804

Feitelson MA, Sun B, Satiroglu Tufan NL, Liu J, Pan J, Lian Z (2002) Genetic mechanisms of hepatocarcinogenesis. Oncogene 21: 2593-2604

Goddard S, Williams A, Morland C, Qin S, Gladue R, Hubscher SG, Adams DH (2001) Differential expression of chemokines and chemokine receptors shapes the inflammatory response in rejecting human liver transplants. Transplantation 72: 1957-1967

Hatch HM, Zheng D, Jorgensen ML, Petersen BE (2002) SDF-1alpha/ CXCR4: a mechanism for hepatic oval cell activation and bone marrow stem cell recruitment to the injured liver of rats. Cloning Stem Cells 4: $339-351$

Helbig G, Christopherson II KW, Bhat-Nakshatri P, Kumar S, Kishimoto H, Miller KD, Broxmeyer HE, Nakshatri H (2003) NF-kappaB promotes breast cancer cell migration and metastasis by inducing the expression of the chemokine receptor CXCR4. J Biol Chem 278: 21631-21638

Kwak MK, Hur K, Kim WH, Lee HJ, PArk DJ, Yang HK (2004) Expression of chemokine receptors in human gastric cancer tissues. 2004 Proceedings of the AACR 95th Annual Meeting of the AACR, Orlando, USA; 45, Abstract \# 1900

Larverdiere C, Hoang BH, Yang R, Sowers R, Qin J, Meyers PA, Huvos AG, Healey HJ, Gorlick R (2004) CXCR4 expression in osteosarcoma correlates with metastatic behaviour and outcome in patients. 2004 Proceedings of the AACR 95th Annual Meeting of the AACR, Orlando, USA; 45, Abstract \#1772

Mavier P, Martin N, Couchie D, Preaux AM, Laperche Y, Zafrani ES (2004) Expression of stromal cell-derived factor-1 and of its receptor CXCR4 in liver regeneration from oval cells in rat. Am J Pathol 165: 1969-1977

Mehata SA, Christopherson II KW, Broxmeyer HE, Kopelovich L, Goulet RJ, Nakshatri H (2004) Understanding the metastatic switch in breast

cancer: role of $\mathrm{p} 53$ on expression of CXCR4, a chemokine receptor involved in site-specific metastasis. 2004 Proceedings of the AACR 45, Abstract \#3331

Mitra P, De A, Ethier MF, Mimori K, Kodys K, Shibuta K, Mori M, Madison JM, Miller-Graziano C, Barnard GF (2001) Loss of chemokine SDF1alpha-mediated CXCR4 signalling and receptor internalization in human hepatoma cell line HepG2. Cell Signal 13: 311-319

Mori $\mathrm{T}$, Doi R, Koizumi M, Toyoda E, Ito D, Kami K, Masui $\mathrm{T}$, Fujimoto K, Tamamura H, Hiramatsu K, Fujii N, Imamura M (2004) CXCR4 antagonist inhibits stromal cell-derived factor 1-induced migration and invasion of human pancreatic cancer. Mol Cancer Ther 3: $29-37$

Murakami T, Maki W, Cardones AR, Fang H, Tun Kyi A, Nestle FO, Hwang ST (2002) Expression of CXC chemokine receptor-4 enhances the pulmonary metastatic potential of murine B16 melanoma cells. Cancer Res 62: $7328-7334$

Murdoch C (2000) CXCR4: chemokine receptor extraordinaire. Immunol Rev 177: $175-184$

Parkin DM, Bray FI, Devesa SS (2001) Cancer burden in the year 2000. The global picture. Eur J Cancer 37(Suppl 8): S4-S66

Phillips RJ, Burdick MD, Lutz M, Belperio JA, Keane MP, Strieter RM (2003) The stromal derived factor-1/CXCL12-CXC chemokine receptor 4 biological axis in non-small cell lung cancer metastases. Am J Respir Crit Care Med 167: $1676-1686$

Richard CL, Tan EY, Blay J (2004) Adenosin increases cell-surface CXCR4 expression on HT-29 human colorectal carcinoma cells. 2004 Proceedings of the AACR 95th Annual Meeting of the AACR, Orlando, USA; 45, Abstract \#3330

Rubin JB, Kung AL, Klein RS, Chan JA, Sun Y, Schmidt K, Kieran MW, Luster AD, Segal RA (2003) A small-molecule antagonist of CXCR4 inhibits intracranial growth of primary brain tumors. Proc Natl Acad Sci USA 100: $13513-13518$

Schimanski CC, Schwald S, Simiantonaki N, Jayasinghe C, Gonner U, Wilsberg V, Junginger T, Berger MR, Galle PR, Moehler M (2005) Effect of chemokine receptors CXCR4 and CCR7 on the metastatic behavior of human colorectal cancer. Clin Cancer Res 11: 1743-1750

Staller P, Sulitkova J, Lisztwan J, Moch H, Oakeley EJ, Krek W (2003) Chemokine receptor CXCR4 downregulated by von Hippel-Lindau tumour suppressor pVHL. Nature 425: 307-311

Stetler-Stevenson WG, Kleiner DE (2001) Molecular Biology of Cancer: Invasion and Metastases. Vol. 6. Principles and Practice of Oncology Lippincott \& Wilkins

Terada R, Yamamoto K, Hakoda T, Shimada N, Okano N, Baba N, Ninomiya Y, Gershwin ME, Shiratori Y (2003) Stromal cell-derived 
factor-1 from biliary epithelial cells recruits CXCR4-positive cells: implications for inflammatory liver diseases. Lab Invest 83: 665 - 672

Thorgeirsson SS, Grisham JW (2002) Molecular pathogenesis of human hepatocellular carcinoma. Nat Genet 31: 339-346

Uchida D, Begum NM, Almofti A, Nakashiro K, Kawamata H, Tateishi Y, Hamakawa H, Yoshida H, Sato M (2003) Possible role of stromal-cellderived factor-1/CXCR4 signaling on lymph node metastasis of oral squamous cell carcinoma. Exp Cell Res 290: 289-302

Wingo PA, Cardinez CJ, Landis SH, Greenlee RT, Ries LA, Anderson RN, Thun MJ (2003) Long-term trends in cancer mortality in the United States, 1930 - 1998. Cancer 97: $3133-3275$
Zeelenberg IS, Ruuls-Van Stalle L, Roos E (2003) The chemokine receptor CXCR4 is required for outgrowth of colon carcinoma micrometastases. Cancer Res 63: 3833-3839

Zhang Y, Foudi A, Geay JF, Berthebaud M, Buet D, Jarrier P, Jalil A, Vainchenker W, Louache F (2004) Intracellular localization and constitutive endocytosis of CXCR4 in human CD34+ hematopoietic progenitor cells. Stem Cells 22: 10151029

Zlotnik A, Yoshie O (2000) Chemokines: a new classification system and their role in immunity. Immunity 12: 121127 